\title{
Nonsurgical management of spinal stenosis: how evidence-based are we?
}

\author{
Harsha Shanthanna, MD
}

Received: 5 November 2010/Accepted: 2 December 2010/Published online: 18 December 2010

(C) Canadian Anesthesiologists' Society 2010

\section{To the Editor,}

I was interested to read the article by Tran et al. published in the July 2010 issue of the Journal. ${ }^{1}$ The authors are to be credited for dealing with the challenges of determining the current best evidence for nonsurgical interventions for lumbar spinal stenosis (LSS). However, based on limitations of the cited publications, the conclusions that can be drawn are limited. Regardless of how the evidence was compiled, if the underlying studies themselves are flawed, the resultant reviews based on that evidence are limited with respect to the conclusions and inferences that can be drawn for treating patients with this unfortunate pain complex.

Lumbar spinal stenosis is a clinical syndrome of buttock or leg pain, with or without back pain, and it is associated with decreased lumbar spinal canal space. ${ }^{2}$ There are no specific criteria to diagnose this condition. The heterogeneity of LSS symptoms has been well analyzed. ${ }^{2,3}$ Clinically, neurogenic claudication (NC) is considered to be a specific feature; the frequency of $\mathrm{NC}$ varies from $23 \%$ to $94 \%$ depending on the selection criteria and the definition used. ${ }^{3}$ Pain observed with NC is often poorly localized with no correlation to central or lateral canal narrowing. In the study by Goh et al., $62 \%$ of patients had back pain and $61 \%$ of patients had NC. Predominant back pain has other possible diagnoses, including spondylolisthesis, which is considered by many to be a confounding factor that should be excluded from the analyses. In the review by Tran et al., no study was excluded on the basis of the definition of intervention allocation or primary and secondary outcomes. Only three of the reported studies included under epidural anesthesia used fluoroscopic guidance. Incorrect needle

H. Shanthanna, MD ( $₫)$

McMaster University, Hamilton, ON, Canada

e-mail: harshamd@gmail.com placement with non-fluoroscopically-guided epidural analgesia could be as high as $30 \%$. In two studies, neurogenic claudication was not considered for inclusion criteria. Cuckler et al. reported a lumbar epidural approach without fluoroscopy. ${ }^{4}$ Surprisingly, a second epidural was given for ethical reasons and not technical failures. In the only positive study evaluating calcitonin, a crossover design was used after a two-month washout period. ${ }^{5}$ Findings included a decrease in pain scores for three months. In Group 1 (placebo), there was a trend towards decreased pain scores, even after three months.

It is difficult to evaluate the pharmacodynamics of a medication in patients with chronic pain, especially with drugs having unknown mechanisms of action, including epidural steroids. Even in patients with LSS, prolonged effects are possibly associated with changes in central nervous system dynamics. The guidelines advanced by Watters et al. seem to differ from those published in the review by Tran et al., both for calcitonin and epidural steroids. ${ }^{2}$

Conflicts of interest The author has received no funding from any source with regard to this work. There are no commercial or noncommercial affiliations associated.

\section{References}

1. Tran DQH, Duong S, Finlayson RJ. Lumbar spinal stenosis: a brief review of the nonsurgical management. Can J Anesth 2010; 57: 694-703.

2. Watters WC 3rd, Baisden J, Gilbert TJ, et al. Degenerative lumbar spinal stenosis: an evidence-based clinical guideline for the diagnosis and treatment of degenerative lumbar spinal stenosis. Spine $\mathbf{J}$ 2008; 8: 305-10.

3. Goh KJ, Khalifa W, Anslow P, Cadoux-Hudson T, Donaghy M. The clinical syndrome associated with lumbar spinal stenosis. Eur Neurol 2004; 52: 242-9. 
4. Cuckler JM, Bernin PA, Wiesel SW, Booth RE Jr, Rohman RH, Pickens GT. The use of epidural steroids in the treatment of lumbar radicular pain. A prospective, randomized, double-blind study. J Bone Joint Surg Am 1985; 67: 63-6.

5. Eskola A, Pohjolainen T, Alaranta H, Soini J, Tallroth K, Slätis $P$. Calcitonin treatment in lumbar spinal stenosis: a randomized, placebo-controlled, double-blind, cross-over study with one-year follow-up. Calcif Tissue Int 1992; 50: 400-3.

\section{Reply}

We thank Dr. Shanthanna for his interest in our review article on lumbar spinal stenosis (LSS) and welcome the opportunity to address his comments.

With regard to the clinical relevance of our conclusions, Dr. Shanthanna is concerned that studies were not excluded based on the definition of intervention allocation or outcome. As indicated in our discussion, the randomized controlled trials (RCTs) on LSS are heterogeneous in nature. For this very reason, we performed a narrative review rather than attempt a meta-analysis that would have been flawed.

Another criticism, which concerns the study by Cuckler et al., ${ }^{1}$ is the fact that epidural injections were not performed with fluoroscopic guidance. Although we agree that epidurals may be less reliable without fluoroscopy, we fail to understand the logic of this argument. Studies by Cuckler et $a l .{ }^{1}$ as well as Fukusaki et $a .^{2}{ }^{2}$ did not compare epidurals to another therapeutic modality. Instead, palpation-guided epidural blocks were performed in all patients; the randomization pertained to the addition of steroids (or saline) to local anesthetics. Thus, technical failure (due to the omission of fluoroscopy) would have occurred in both groups. Furthermore, Manchikanti et $a .^{3}$ clearly showed that the addition of steroids to lidocaine conferred no additional benefits, even when caudal blocks were performed with fluoroscopy.

Dr. Shanthanna criticizes the two-month washout period used in the study by Eskola et al. ${ }^{4}$ by referring to a trend toward decreasing levels of pain even after three months (placebo group). However, great caution must be exercised whenever commenting on "trends", as a review of Eskola et al.'s data clearly shows that levels of static and dynamic pain did not change significantly from three to six months $\left(P=0.35\right.$ and 0.21 , respectively) ${ }^{4}$

Finally, with regard to calcitonin and epidural steroids, our recommendations differ from those of Watters et al. ${ }^{5}$
The latter guidelines were based on more variable levels of evidence (including expert opinion). Specifically, the studies analyzed (RCT or other) for calcitonin and epidural steroids were not listed. Thus, we were unable to comment on their findings. However, we do emphasize that several of our conclusions differ from those of previous reviews (the explanations are clearly detailed in Table 5).

In conclusion, we recognize that many published RCTs in pain medicine contain reporting or methodological limitations. At the same time, physicians require critical summaries of best available evidence to guide their practice. Until such time that better evidence can be derived from the systematic review of flawless studies, clinicians should be encouraged to base their acquisition of knowledge on cautious interpretation of current (best) evidence.

Competing interests None declared.

\section{References}

1. Cuckler JM, Bernini PA, Wiesel SW, Booth RE Jr, Rothman RH, Pickens GT. The use of epidural steroids in the treatment of lumbar radicular pain. A prospective, randomized, double-blind study. J Bone Joint Surg Am 1985; 67: 63-6.

2. Fukusaki M, Kobayashi I, Hara T, Sumikawa K. Symptoms of spinal stenosis do not improve after epidural steroid injection. Clin J Pain 1998; 14: 148-51.

3. Manchikanti L, Cash KA, McManus CD, Pampati V, Abdi S. Preliminary results of a randomized, equivalence trial of fluoroscopic caudal epidural injections in managing chronic low back pain: Part 4-spinal stenosis. Pain Phys 2008; 11: 833-48.

4. Eskola A, Pohjolainen T, Alaranta H, Soini J, Tallroth $K$, Slatis $P$. Calcitonin treatment in lumbar spinal stenosis: a randomized, placebo-controlled, double-blind, cross-over study with one-year follow-up. Calcif Tissue Int 1992; 50: 400-3.

5. Watters WC 3rd, Baisden J, Gilbert TJ, et al. Degenerative lumbar spinal stenosis: an evidence-based clinical guideline for the diagnosis and treatment of degenerative lumbar spinal stenosis. Spine J 2008; 8: 305-10.

Silvia Duong, PharmD

Roderick J. Finlayson, MD

De Q.H. Tran, MD

Montreal General Hospital, McGill University,

Montreal, QC, Canada 